I have to thank Dr. Edmund Cautley and Dr. Philip Hamill for their kindness in allowing me to publish these notes on their cases.

\section{AN UNUSUALLY LARGE RENAL CALCULUS.}

By H. B. Mylvaganam, F.R.C.S. Eng.,

SURGEON IN CHARGE OF THE VTOTORIA HOSPITAL, BANGALORE, S. INDIA.

THE interest in the following case lies in the circum. stance that it has been possible for a stone to attain such an enormous size in the renal pelvis without manifesting any clinical sign or symptom in its early stage.

History of the case.-Patient, a male, H. R. P., aged about 50 years was admitted into hospital on Nov. 20th, 1919, for an abdomina tumour, which, he said, he noticed about six months ago and which had increased in size gradually ever since. About a year previous to the appearance of the tumour he noticed blood in the urine and burning sensation during micturition in the region of the bladder. But during the last six months he had not noticed any blood in the urine, but the quantity of urine had gradually diminished since the appearance of the tumour. He never had any renal colic, nausea, or vomiting, but his appetite had failed since the appearance of the tumour and he had become emaciated. Present condition: Patient is pale, anæmic, and emaciated, and looks aged. His teeth are covered with tarter and he has pyorrhoea Tongue coated and moist. No temperature. Appetite impaired. Has looseness of bowels for the last 12 days.

Local examination: A tumour, of about the size of a mediumsized coconut, is seen to occupy the region of the right hypochondrium, right lumbar, and the right half of the epigastrium and umbilical regions. On palpation it is fairly smooth, rounded, and hard. It is not freely movable. No fluid thrill is felt in it. It is dull on percussion, and the dullness is continuous with the liver dullness. There is pain felt in the tumour on deep pressure. Colonic resonance present. The opposite kidney cannot pressure. Colonic resonance present. The opposite kidney cannot
be felt. The other abdominal organs appear to be normal.
Respiratory system is pormal. Heart sounds are weak, but no Respiratory system is normal. Heart sounds are weak, but no
dilatation noted. Pulse small, frequent, and compressible, about 110 per minute.

Urine: Sp. gravity, 1025; colour, faintly reddish ; reaction,
Urinute. slightly alkaline; sugar and albumin, nil; microscopic examina slightly alkaline; sugar and albumin, nil; micros

Diagnosis: On account of its rapid growth during the last six months, as stated by the patient, the hardness of the tumour months, as stated by the patient, the hardness of the tumour, blood in the urine during the early stage, and rapid emaciation blood in the urine during the early stage, and rapid emaciation of a renal calculus was never entertained.

of a renal calculus was never entertained. Operation (28/10/19). - As the patient was in a very weak state
and emaciated, the chances of a successful operation were very and emaciated, the chances of a successful operation were very remote, but he was anxious that something should be done to
relieve his sufferings. So with great reluctance I consented to relieve his sufferings. So with great reluctance I consented to perform the operation. As the tumour was a large one it was instead of the usual lumbar incision. Accordingly an incision wa made along the right linea semilunaris and the abdominal cavity opened. The intestines having been packed away, the peritoneum over the tumour was incised longitudinally and the two halve separated from the surface of the tumour to facilitate removal. O feeling the tumour now it felt stony hard, with a thin capsule surrounding it. It did not present the appearance of a new growth. As there was no time to be lost I proceeded with its removal, which was attended with diffculty on account of its adhesions. The fatty capsule of the kidney was adherent to the diaphragm and the ribs posteriorly, and at its medial end the tumour was als adherent to the inferior vena cava to a small extent. After ligaturing the renal artery, vein, and ureter separately I was able to remove the whole tumour intact except the small portion adherent to the inferior vena cava, which was left behind. It wa only this small area which appeared to be malignant at all. Th peritonenm over the posterior abdominal wall was approximated with fine catgut continuous suture, and the abdominal incision wo closed in three separate layers. The patient rallied from the operation in an hour's time became conscious and was able to answer questions. Rectal saline was given. Later in the evenin he showed signs of collapse. Intravenous saline and pituitrin injeetions were freely given, but of no avail. He died about 14 hours after the operation.

Morbid anatomy. - The tumour is smooth, round, and surrounded with a capsule formed by the thinned-out kidney substance and pelvis. The kidney is elongated, but much reduced in size, and pelvis. The kidney is elongated, but much reduced in size, an capsule a large stone, dark brown in colour and granular in appear ance, was found to occupy the cavity of the pelvis. It was easily ance, was found to occupy the cavity of the pelvis. It was easily
detached from the cavity. The whole tumour weighs $4 \frac{1}{4} 1 \mathrm{~b}$. At its upper and medial aspect the tumour is friable and has a granular upper and medial aspect the tumour is friable and has a granularlooking surface. It was at this spot that it was adherent to the
inferior vena cava The stone weighs $3 \mathrm{Ib}$. Its largest diameter is inferior vena cava The stone weighs $3 \mathrm{lb}$. Its largest diameter in $6 \frac{1}{2}$ in., the shortest diameter is 6 in., and its circumference is $15 \frac{1}{2}$ in.
There was no other stone present. The stone was covered with creamy pus.

As far as I know, a renal calculus weighing $3 \mathrm{lb}$. has never been recorded, and what is more surprising than the size of the stone is that the patient should not have felt any inconvenience whatever during the period it had been slowly growing until six months previous to his admission to the Victoria Hospital. A calculus of this size should have taken several years to form by slow deposit in the ordinary course of events.

\section{attediral Socteties.}

\author{
ROYAL SOCIETY OF MEDICINE.
}

\section{SECTION FOR THE STUDY OF DISEASE IN CHILDREN.}

AT a meeting of this section of the Royal Society of Medicine, held on Oct. 22nd, Dr. FREDERICK LANGMEAD the President, having thanked the members for the honour they had done him in electing him to the chair, asked for a full measure of their support, by showing cases and by submitting papers to the section. Owing to the days on which the Section meets, early notification of the titles of the cases to be shown is very advantageous, as only in this way can an announcement be published in the diary card of the Society and the medical papers. He was empowered by the Council to state that a meeting would be held on each of the fixed dates, and that in the unlikely event of insufficient material being forthcoming for an ordinary meeting, an informal discussion would take place.

Exhibition of Clinical Cases. Severe Ancemia.

Dr. H. Chodak GrEgory showed a case of Serere Anæmia.

The patient, a female child, aged 1 year and 5 months, had first come under observation nearly two months ago for pallor, loss of appetite, and drowsiness of one months' duration. Vomiting had occurred once or twice, the stools were pale and offensive, and there had been no hæmorrhages. She had been breast-fed for three months and then fed on condensed sweetened milk. There was no tuberculosis in the family and nothing to suggest syphilis. The spleen reached to the level of the umbilicus and the liver was also enlarged to two fingers breadth below the costal margin in the nipple line. No lymphatic glandular enlargement of consequence; heart, lungs, and urine normal. Stools pale, otherwise normal. Blood count red corpuscles, $3,500,000$; colour index, 0.16 ; white cells 1880 ; polymorphs, 36.5 per cent.; small lymphocytes, 53 per cent.; large lymphocytes, 5.5 per cent.; large hyalines, 2.75 per cent.; eosinophils, 1.75 per cent.; mast cells, 0.5 per cent. Six normoblasts were seen in counting 400 white cells. Fragility of red cells normal. The Wassermann reaction was negative. Three days later the blood count showed a decrease of red cells and a slight increase of white. The general condition become steadily worse, the temperature raised every night, the pulse rapid and weak, and the right side of the heart considerably dilated. Eight days after admission the child suddenly collapsed and seemed to be dying, but was revived by transfusion of $20 \mathrm{c.cm}$. of the mother's blood in 10 per cent. sodium citrate into the left external jugular vein. A second transfusion of $10 \mathrm{c.cm}$. of blood was done four days later. Steady improvement had followed. Apart from the transfusions, treatment had been limited to small doses of iron and arsenic, and to camphor injections when a stimulant was needed.

Dr. J. H. THURSFIELD congratulated Dr. Gregory on the excellent result of the treatment. He had no hesitation in diagnosing the case as one of von Jaksch's anæmia, a condition which he regarded as a distinct clinical entity having closer relation to spleno-medullary leukæmia than to other forms of anæmia. An unusual feature in this case was the absence of hæmorrhages. From a large series of cases which he had studied in collaboration with Dr. Drysdale, he was able to say that though fatalities occurred from intercurren diseases, to which these children were liable, those who survived got well completely.-Dr. H. C. CAMERON referred to the food which this child had been taking, during the development of the anæmia-viz., condensed sweetened milk -and thought that defective dieting must be taken into account in the consideration of the anæmia of infants. It was generally recognised that after the cessation of breast-feeding, iron-containing constituents were necessary, and also that the reaction of the hæmopoietic system to small defects produced marked alteration of the blood in infants.-Dr. ERIC PRITCHARD agreed with all that Dr. Cameron had said and referred to similar cases described by Dr. $P$ ' Parkinson, which appeared to have followed infection by scarlet fever. He had himself observed such a case. 